\title{
Lepage, Élise. Géographie des confins. Espaces et écriture chez Pierre Morency, Pierre Nepveu
} et Louis Hamelin. Ottawa : David, 2015. 318 p.

«Le Canada a trop de géographie et pas assez d'histoire », écrivait John A. Macdonald, l'un des Pères de la Confédération (cité dans Lepage). Pourtant, ce n'est que depuis une vingtaine d'années environ qu'on observe un nombre croissant de recherches sur la représentation de l'espace et des lieux dans les différentes disciplines des sciences humaines et sociales. C'est dans ce courant de théorisation de la spatialité que s'inscrit Géographie des confins, un ouvrage captivant qui invite le lecteur à repenser les multiples imaginations des confins et des lieux dans la littérature québécoise.

Dans l'introduction, Élise Lepage brosse un panorama complet de l'évolution de l'histoire de la littérature au Québec, dont le passage à la « modernité a été fortement associé à la ville, alors que les régions étaient identifiées à un héritage littéraire et idéologique passéiste » (quatrième de couverture). Dans l'ensemble, elle relève avec brio le défi de (re)définir les modes de conceptualisation et de représentation des espaces évoqués dans les textes (romans, poèmes, essais critiques et littéraires) de Pierre Morency, Pierre Nepveu et Louis Hamelin. Elle nous présente d'abord une vision esthétique et statique des paysages et une « cartographie littéraire » des lieux d'ici et d'ailleurs (États-Unis et reste du Canada), incluant ceux des confins les plus reculés de la province, en passant par les petits villages. Puis, Lepage s'intéresse non plus à l'espace en soi, mais à l'espace que nous occupons : un espace que nous transformons, et qui en même temps contribue à nous définir (association identité/territorialité). Par nos déplacements, le territoire devient lieu de rencontre avec l'Autre (association spatialité/altérité). Enfin, l'ouvrage se termine avec notre univers domestique, ces espaces avec lesquels nous entretenons un lien plus intime (peau, vêtement et maison) et qui nous permettent par la suite d'appréhender les espaces plus vastes, comme le paysage.

Bref, Lepage offre une vue d'ensemble fascinante et bien structurée. Elle propose différentes visions de la spatialité, que ce soit d'un point de vue à la fois sédentaire et nomade, familier et étranger, intime et vaste, et elle réussit l'exploit de nous guider à travers le dédale des termes associés avec la géographie, les lieux, les confins, les paysages. Géographie des confins représente une excellente ressource pour tous les chercheurs et les étudiants universitaires qui s'intéressent à la spatialité dans le domaine de la littérature et des sciences humaines.

Isabelle Fournier 